\title{
Molecular characterization and genetic diversity of bovine Kobuvirus, Brazil
}

\author{
Marcelo Candido ${ }^{1}$ - Maria Cryskely Agra Batinga ${ }^{1}$ - Anna Luiza Farias Alencar ${ }^{1}$. \\ Sabrina Ribeiro de Almeida-Queiroz ${ }^{1} \cdot$ Maria da Glória Buzinaro $^{2}$. \\ Márcia Cristina Livonesi ${ }^{3} \cdot$ Andrezza Maria Fernandes $^{1} \cdot$ Ricardo Luiz Moro de Sousa $^{1}$
}

Received: 23 May 2016/ Accepted: 6 September 2016/Published online: 13 September 2016

(C) Springer Science+Business Media New York 2016

\begin{abstract}
It is suggested that Bovine kobuvirus (BKV) is involved in the etiology of gastroenteric diseases especially among calves; however, this association remains unknown. This study evaluated 216 fecal samples from cattle with and without diarrhea symptoms obtained from different regions of Brazil. A 216 bp fragment of the BKV 3D gene was amplified by RT-PCR in $14.4 \%(31 / 216)$ of the studied samples, and 17 samples were subjected to nucleotide sequencing. All positive samples were obtained from animals aged less than 5 months, and most of animals presented diarrhea $(p<0.05)$. Phylogenetic analyses showed that the obtained sequences were grouped within the genogroup 2 of BKV forming subclades specific for each Brazilian municipality sampled. In addition, the alignment of the sequences revealed differences of nucleotides between sequences from different locations.
\end{abstract}

Edited by William Dundon.

Electronic supplementary material The online version of this article (doi:10.1007/s11262-016-1391-1) contains supplementary material, which is available to authorized users.

Marcelo Candido

marcelo.c@usp.br

1 Department of Veterinary Medicine, Faculty of Animal Science and Food Engineering, University of São Paulo (FZEA/USP), Avenida Duque de Caxias Norte, 225, Jardim Elite, Pirassununga, São Paulo 13635-900, Brazil

2 Department of Preventive Veterinary Medicine and Animal Reproduction, São Paulo State University (UNESP), Via de Acesso Prof. Paulo Donato Castellani, Rural, Jaboticabal, São Paulo 14884-900, Brazil

3 Department of Clinical Analysis, Alfenas Federal University (UNIFAL), Rua Gabriel Monteiro da Silva, 700, Centro, Alfenas, Minas Gerais 37130-000, Brazil
Our results indicate for the first time that there is a regional genotypic differentiation of BKV in Brazil.

Keywords Picornavirus - Diarrhea - Cattle diseases . Molecular epidemiology

Kobuvirus is a genus of viruses belonging to the family $P i$ cornaviridae [1]. Three species are currently known: Aichi virus A (Aichi virus, AIV) [2], Aichi virus B (Bovine kobuvirus, BKV) [3], and Aichi virus C (Porcine kobuvirus, $\mathrm{PKV}$ ) [4]. Kobuvirus-like infections have been described in other animal species such as dogs [5], bats [6], boars [7], sheep [8], red foxes [9], goats [10], cats [11], rodents [12], ferrets [13], and birds [14]. Kobuviruses have small non-enveloped virions with icosahedral symmetry and diameter of 27-30 nm. The virus genome is composed of single-stranded positive sense RNA, ranging from 8.2 to $8.4 \mathrm{~kb}$ [15]. Its genome encodes a single large polyprotein that is later cleaved to produce active viral proteins, and it is organized into three structural regions (VP0, VP3 and VP1), seven nonstructural regions $(2 \mathrm{~A}-2 \mathrm{C}$ and $3 \mathrm{~A}-3 \mathrm{D})$, and a leader protein (L). The 3D region encodes RNA-dependent RNA polymerase (RdRp) and comprises a region that is conserved among kobuviruses [3]. Aichi virus detection in water and sewage indicates that this virus can be transmitted by the fecal-oral route [16, 17]. The main clinical symptoms associated with AIV infection are diarrhea, abdominal pain, nausea, vomiting, and fever [2]. However, it is still not clear whether there is an association between gastroenteritis (including diarrhea) and BKV infection.

$\mathrm{BKV}$ is divided into four different genogroups, and has been detected in diarrheic and asymptomatic cattle in Japan [3], Thailand [18], South Korea [19], Hungary [20], Netherlands [21], Belgium [22], Italy [23], Brazil [24], and 
China [25]. Some studies have also indicated genetic distinctions among BKV detected in different locations $[25,26]$. Infections caused by this agent in Brazil have been poorly characterized. In this study, we have detected and analyzed the genotypic differentiation of BKV present in fecal samples obtained from cattle herds from several Brazilian locations.

Fecal samples from 216 (either diarrheic or healthy) animals were collected from July 2007 to June 2013. The samples were originated from cattle herds from the six Brazilian states: São Paulo (96 samples, $44.4 \%$ ), Minas Gerais (92 samples, $42.6 \%$ ), Paraná (3 samples, $1.4 \%$ ), Mato Grosso do Sul (6 samples, $2.8 \%$ ), Rio Grande do Sul (15 samples, $6.9 \%$ ), and Rondônia (4 samples, $1.9 \%$ ). Animals were classified according to their gender, age, dairy or beef aptitude, and breeding system. Age classification comprised three categories: calf (less than 6 months of age), young (between 6 months and 2 years of age), and adults (above 2 years of age). According to this classification system, of all tested animals, $22(10.2 \%)$ were adults, 45 (20.8\%) were young, and $149(69.0 \%)$ were calves. Forty-one animals (19.0\%) were male and 175 $(81.0 \%)$ were females. Ten animals $(4.6 \%)$ were raised in extensive farming conditions and $206(95.4 \%)$ in semiintensive or intensive farming. Thirteen animals $(6.0 \%)$ were beef cattle and $203(94.0 \%)$ were dairy cattle. Eighty-nine animals $(41.2 \%)$ presented with symptoms of diarrhea, whereas 127 animals $(58.8 \%)$ were not.

Sample harvesting was performed according to Hoet et al. [27]. RNA was extracted from $300 \mu \mathrm{L}$ of fecal suspension with TRIzol $^{\mathrm{TM}}$ (Life Technologies, USA), according to the manufacturer's instructions. Reverse transcription was performed using the ImProm-II ${ }^{\mathrm{TM}} \mathrm{Rev}$ erse Transcription System (Promega, USA) and random primers (Invitrogen, USA), in accordance with the manufacturer's instructions. The UNIV-kobu-F/R primers were used to amplify a fragment of $216 \mathrm{bp}$ of the 3D region (RNA-dependent RNA polymerase) of the BKV genome [20]. An amplicon of the bovine actin gene as described by Renshaw et al. [28] was used as internal control for DNA presence and quality. PCR reactions were performed using GoTaq $^{\text {TM }}$ Colorless Master Mix (Promega, USA), according to the manufacturer's instructions. Nuclease-free water was used as a negative control.

The amplified products were gel extracted and sequenced directly on both strands with the same primers used in the PCR, in an automated ABI 3730 DNA Analyser (Applied Biosystems, USA).

The sequence similarities between the obtained sequences and BKV reference sequences were performed using the BLAST software, version 2.0 [29] with consensus sequences obtained from the CAP3 Contig software [30]. The editing and sequence alignments were performed using
ClustalW software, version 1.4 [31], implemented in BioEdit Sequence Alignment Editor software, version 7.0.9 [32]. Distance matrices were generated from the percentages of similarity/identity between nucleotide and deduced amino acid sequences using the global alignment algorithm tool in the MatGAT software, version 2.0 [33]. Phylogenetic reconstruction was generated using nucleotide sequences, according to the Neighbor-Joining (NJ) method, Kimura 2-parameter model. In this analysis, we used bootstrap nodal support for 1000 pseudoreplicates in MEGA software, version 5.0 [34].

Association between RT-PCR results and clinical results was analyzed by the Chi square test, the confidence limits for the test was set at $95 \%(p<0.05)$.

The RT-PCR results for amplification of the 3D gene fragment from 216 stool samples analyzed showed that 31 $(14.4 \%)$ were positive for BKV. All positive samples were from calves which aged less than 5 months. Regarding gender, the majority of positive samples were from females $(74.2 \%)$. From 31 positive samples, 24 were obtained from animals presenting diarrhea $(77.4 \%)$. The association between the presence of BKV and diarrhea indicated by this method was statistically significant $(p<0.05)$. Among the positive samples, $28(90.3 \%)$, originated from dairy cattle. Regarding the production system, only $9.7 \%$ of the animals were raised in an extensive system, while the majority $28(90.3 \%)$ were from intensive or semi-intensive farms.

Positive samples were obtained from herds located in the following four Brazilian states: 20 (64.5\%) from São Paulo, 5 (16.1\%) from Minas Gerais, 3 (9.7\%) from Rondônia, and 3 (9.7\%) from Rio Grande do Sul (Suppl. Figure 1). Of 31 positive samples, 17 were sequenced and identified as BKV-related sequences. The samples sequenced in this study were clustered within BKV genogroup 2, but differed in specific subclades at the different cities studied (Fig. 1).

Our samples when compared to samples from other countries, representing the four genogroups of BKV, showed identities ranging from 86.0 to $93.0 \%$ (nucleotide) and 91.2 to $100.0 \%$ (deduced amino acid) (Table 1). Specific nucleotide substitutions in certain locations of the gene in the different municipalities sampled are noted, indicating that this virus may be in continuous recombination and/or mutation (Suppl. Table 1).

BKV was detected in $14.4 \%(31 / 216)$ of the samples, similar to a previous study performed in Brazil on 2014, relating an $18.0 \%$ (40/222) positivity rate [24]. Di Martino et al. [23] and Reuter and Egyed [20] reported a positivity of $4.9 \%(7 / 142)$ in Italy and $6.2 \%(2 / 32)$ in Hungary, respectively, while higher positivity rates $(34.9$ and $77.8 \%$ ) were found in China [25] and in Netherlands [21], respectively. 


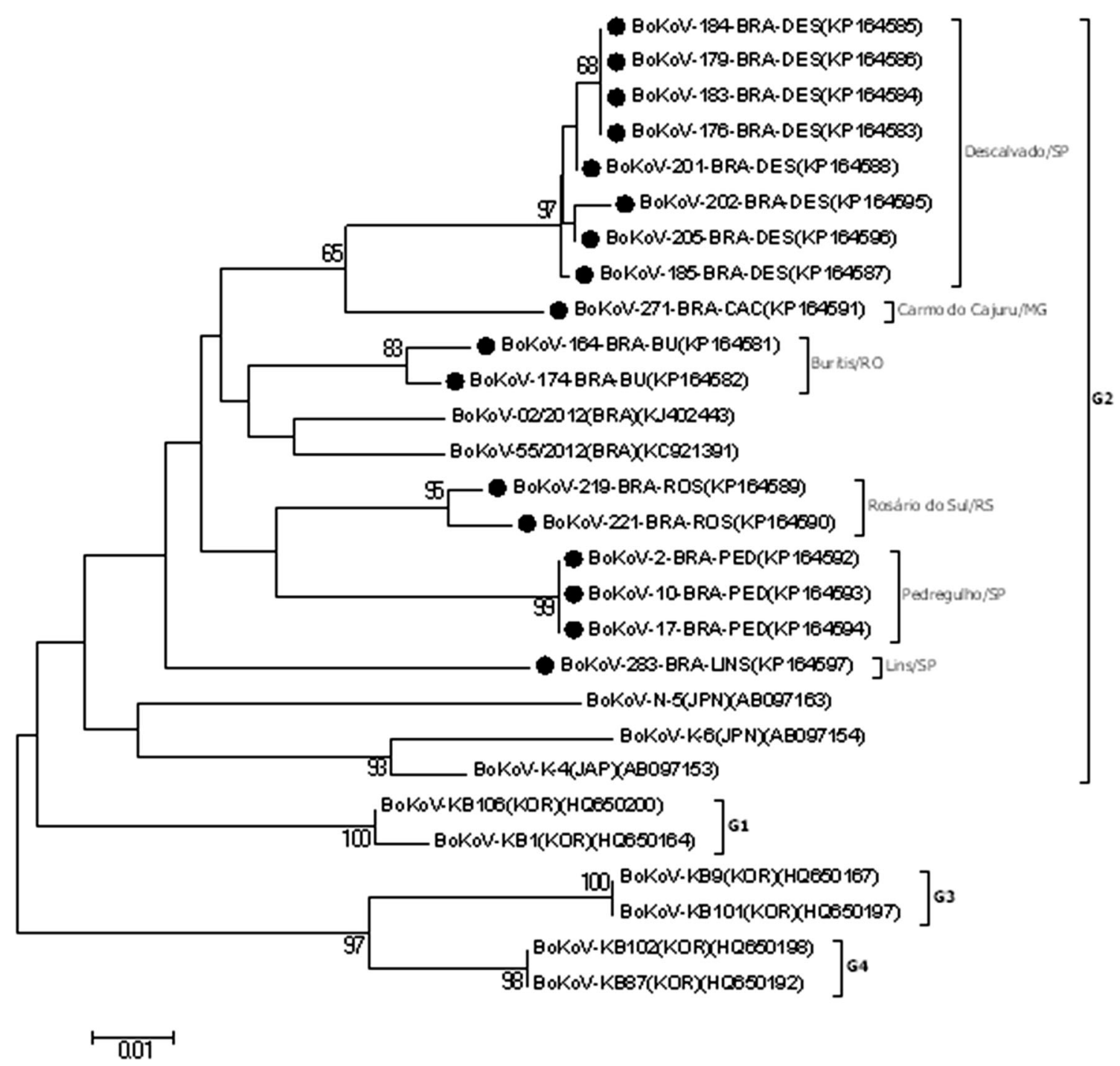

Fig. 1 Cladogram representing phylogenetic reconstruction using a nucleotide fragment of $216-\mathrm{bp}$ product $3 \mathrm{D}$ of $\mathrm{BKV}$, related to the region 7535-7705 of the U-1 sample (GenBank: AB084788). Bootstrap values higher than $50 \%$ for 1000 pseudoreplicates are

The seventeen samples subjected to nucleotide sequencing were collected from six Brazilian locations (Descalvado-SP, Pedregulho-SP, Lins-SP, Carmo do Cajuru-MG, Rosário do Sul-RS and Buritis-RO) (Suppl. Figure 1). The average distance between these municipalities ranges from 200 to $2400 \mathrm{~km}$ [35].

It is suggested that the $3 \mathrm{D}$ region is suitable for the classification of BKV genogroups [26]; thus, the sequenced samples in this study were clustered within the genogroup 2 , forming specific subclades for each sampled municipality (Fig. 1). In addition to the samples sequenced in this study, two sequences obtained from a previous study in Brazil were retrieved from GenBank (BokoV-02/202 and $55 / 2012$ ) and were used for reconstruction of the shown at the nodes. BRA sequences obtained in the present study are labeled with filled circle. GenBank accession numbers are shown on the tree. The scale bar represents the phylogenetic distance between sequences

phylogenetic tree. These samples formed a separate subclade in the same genogroup of the studied sequences; however, there was no precise information about their origin [24]. High rates of viral positivity in animals showing diarrhea symptoms $(p<0.05)$ confirmed the suspicions of previous studies [23, 26]. However, virus detection in diarrheic animals is not a clinical sign in BKVinfected cattle [20]. Experiments using gnotobiotic cattle experimentally infected with BKV are needed to explain whether these viruses are involved in the etiology of diarrhea in these animals.

The prevalence of BKV in calves (all positive animals in this study) as compared to those of other age categories, reinforce the high $\mathrm{BKV}$ detection in animals under 6 


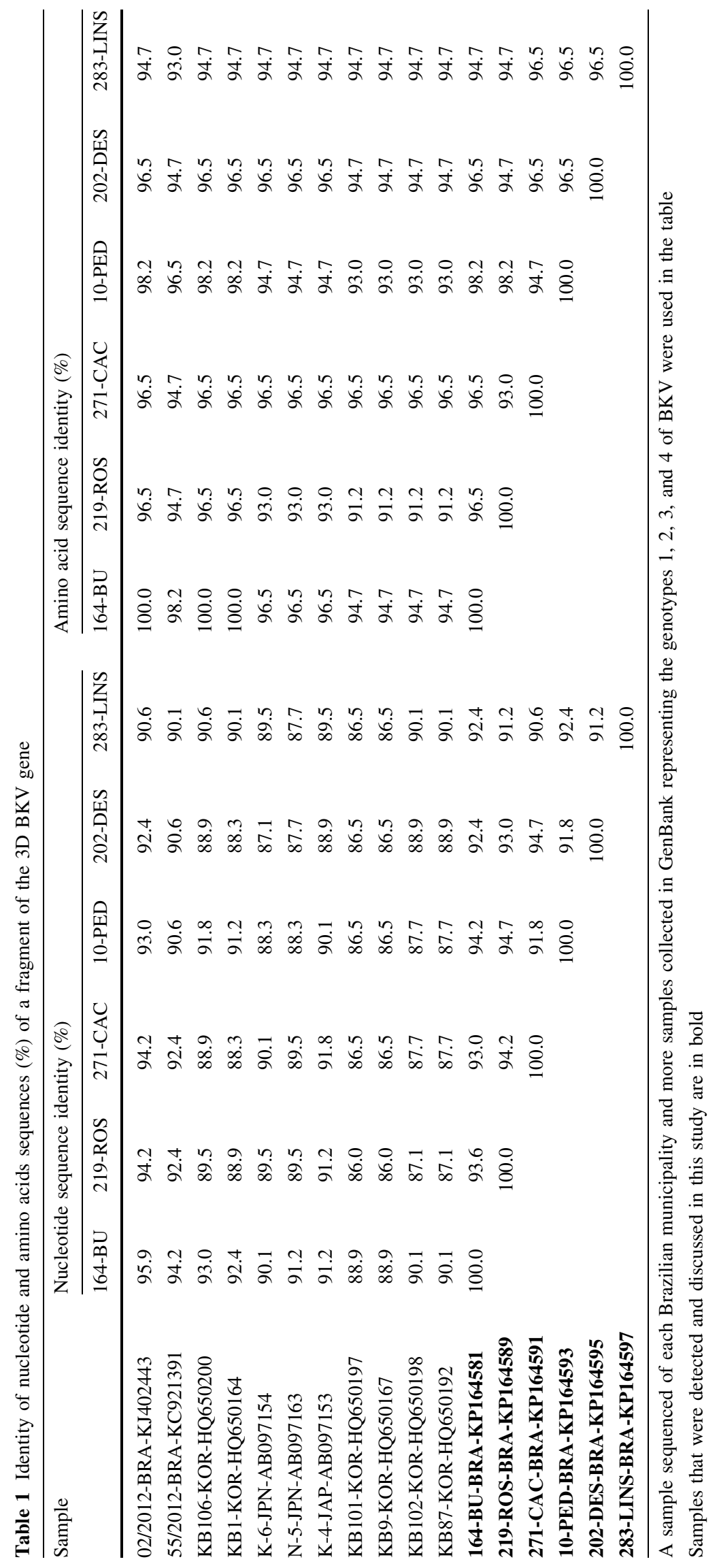


months of age $[23,26]$. The percentage of positive swine animals is smaller with increasing age [36], similar to the results found in cattle.

Our results indicate the regional specificity of the BKV genome in Brazil, similar to the results found by Chang et al. [25], analyzing the VP1 gene in China, where they found genetic diversity among BKV in the country; however, the samples did not show specific geographical characteristic for different sampled regions.

It is suggested that studies with larger fragments or even the complete genome of BKV, should be undertaken in Brazil, for a better understanding of how this virus behaves. Like others picornavirus, it is possible that BKV undergoes recombination events occurring between viruses infecting animals of the same and/or different species [37].

In conclusion, we report for the first time the genotypic differentiation of BKV in Brazil, from samples originating from different regions. Our results contribute to the expansion of knowledge of regional specific characteristics of the BKV genome. The frequency of infection was statistically significant in cattle with diarrhea symptoms, and all positive samples were from calves of less than 5 months of age.

Acknowledgments This research was funded by the Fundação de Amparo à Pesquisa do Estado de São Paulo (FAPESP, No. 2006/52060-3 and 2012/18441-0) and Conselho Nacional de Desenvolvimento Científico e Tecnológico (CNPq, No. 472509/2010-1).

\section{Compliance with ethical standards}

Conflict of interest The authors declare no conflict of interest regarding this work.

Ethical approval All applicable international, national, and/or institutional guidelines for the care and use of animals were followed.

\section{References}

1. A.M.Q. King, F. Brown, P. Christian, T. Hovi, T. Hyypiä, N.J. Knowles, S.M. Lemon, P.D. Minor, A.C. Palmenberg, T. Skern, G. Stanway, Picornaviridae, in Virus taxonomy: seventh report of the International Committee on Taxonomy of Viruses, ed. by M.H.V. Van Regenmortel, C.M. Fauquet, D.H.L. Bishop, E.B. Carstens, M.K. Estes, S.M. Lemon, J. Maniloff, M.A. Mayo, D.J. McGeoch, C.R. Pringle, R.B. Wickner (Academic Press, San Diego, 2000), pp. 657-678

2. T. Yamashita, S. Kobayashi, K. Sakae, S. Nakata, S. Chiba, Y. Ishihara, S. Isomura, J. Infect. Dis. 164, 954-957 (1991)

3. T. Yamashita, M. Ito, Y. Kabashima, H. Tsuzuki, A. Fujiura, K. Sakae, J. Gen. Virol. 84, 3069-3077 (2003)

4. G. Reuter, A. Boldizsar, I. Kiss, P. Pankovics, Emerging. Infect. Dis. 14, 1968-1970 (2008)

5. L. Li, P.A. Pesavento, T. Shan, C.M. Leutenegger, C. Wang, E. Delwart, J. Gen. Virol. 92, 2534-2541 (2011). doi:10.1099/vir.0. 034611-0

6. L. Li, J.G. Victoria, C. Wang, M. Jones, G.M. Fellers, T.H. Kunz, E. Delwart, J. Virol. 84, 6955-6965 (2010)
7. G. Reuter, C. Nemes, A. Boros, B. Kapusinszky, E. Delwart, P. Pankovics, Arch. Virol. 158, 281-282 (2013). doi:10.1007/ s00705-012-1456-y

8. G. Reuter, A. Boros, P. Pankovics, L. Egyed, Emerging. Infect. Dis. 16, 869-870 (2010). doi:10.3201/eid1605.091934

9. R. Bodewes, A. Ruiz-Gonzalez, C.M. Schapendonk, J.M. van den Brand, A.D. Osterhaus, S.L. Smits, Virol. J. (2014). doi:10.1186/ 1743-422X-11-89

10. M.H. Lee, H.Y. Jeoung, J.A. Lim, J.Y. Song, D.S. Song, D.J. An, Virus Genes 45, 186-189 (2012). doi:10.1007/s11262-012-07456

11. N. Carmona-Vicente, J. Buesa, P.A. Brown, J.Y. Merga, A.C. Darby, J. Stavisky, L. Sadler, R.M. Gaskell, S. Dawson, A.D. Radford, Vet. Microbiol. 164, 246-252 (2013). doi:10.1016/j. vetmic.2013.02.014

12. T.G. Phan, B. Kapusinszky, C. Wang, R.K. Rose, H.L. Lipton, E.L. Delwart, PLoS Pathog. (2011). doi:10.1371/journal.ppat. 1002218

13. S.L. Smits, V.S. Raj, M.D. Oduber, C.M. Schapendonk, R. Bodewes, L. Provacia, K.J. Stittelaar, A.D. Osterhaus, B.L. Haagmans, PLoS One (2013). doi:10.1371/journal.pone.0071595

14. P. Pankovics, Á. Boros, T. Kiss, G. Reuter, Arch. Virol. 160, 345-351 (2014). doi:10.1007/s00705-014-2228-7

15. G. Reuter, A. Boros, P. Pankovics, Rev. Med. Virol. 21, 32-41 (2011). doi:10.1002/rmv.677

16. A. Alcalá, E. Vizzi, J. Rodríguez-Díaz, J.L. Zambrano, W. Betancourt, F. Liprandi, Appl. Environ. Microbiol. 76, 4113-4115 (2010). doi:10.1128/AEM.00501-10

17. M. Kitajima, E. Haramoto, C. Phanuwan, H. Katayama, Appl. Environ. Microbiol. 77, 2184-2187 (2011). doi:10.1128/AEM. 02328-10

18. P. Khamrin, N. Maneekarn, S. Peerakome, S. Okitsu, M. Mizuguchi, H. Ushijima, Emerging. Infect. Dis. 14, 985-986 (2008). doi:10.3201/eid1406.070784

19. S.J. Park, H.K. Kim, D.S. Song, H.J. Moon, B.K. Park, Infect. Genet. Evol. 11, 1178-1182 (2011). doi:10.1016/j.meegid.2011. 02.019

20. G. Reuter, L. Egyed, Emerging. Infect. Dis. 15, 822-823 (2009). doi:10.3201/eid1505.081427

21. A.F. Barry, J. Ribeiro, A.F. Alfieri, W.H. van der Poel, A.A. Alfieri, Infect. Genet. Evol. 11, 1811-1814 (2011). doi:10.1016/j. meegid.2011.06.020

22. A. Mauroy, A. Scipioni, E. Mathijs, C. Thys, E. Thiry, Arch. Virol. 154, 1841-1845 (2009). doi:10.1007/s00705-009-0518-2

23. B. Di Martino, F. Di Profio, E. Di Felice, C. Ceci, M.G. Pistilli, F. Marsilio, Arch. Virol. 157, 2393-2396 (2012). doi:10.1007/ s00705-012-1439-z

24. J. Ribeiro, E. Lorenzetti, A.F. Alfieri, A.A. Alfieri, Vet. Res. Commun. 38, 177-182 (2014). doi:10.1007/s11259-014-9600-7

25. J. Chang, Q. Wang, F. Wang, Z. Jiang, Y. Liu, L. Yu, Arch. Virol. 159, 1505-1510 (2014). doi:10.1007/s00705-013-1961-7

26. H.Y. Jeoung, J.A. Lim, W. Jeong, J.K. Oem, D.J. An, Virus Genes 42, 402-406 (2011). doi:10.1007/s11262-011-0593-9

27. A.E. Hoet, P.R. Nielsen, M. Hasoksuz, C. Thomas, T.E. Wittum, L.J. Saif, J. Vet. Diagn. Invest. 15, 205-212 (2003)

28. R.W. Renshaw, R. Ray, E.J. Dubovi, J. Vet. Diagn. Invest. 12, 184-186 (2000)

29. S.F. Altschul, T.L. Madden, A.A. Schäffer, J. Zhang, Z. Zhang, W. Miller, D.J. Lipman, Nucleic Acids Res. 25, 3389-3402 (1997)

30. X. Huang, A. Madan, Genome Res. 9, 868-877 (1999)

31. J.D. Thompson, D.G. Higgins, T.J. Gibson, Nucleic Acids Res. 22, 4673-4680 (1994)

32. T.A. Hall, Nucleic Acids Symp. Ser. 41, 95-98 (1999)

33. J.J. Campanella, L. Bitincka, J. Smalley, BMC Bioinform. 4, 29 (2003). doi:10.1186/1471-2105-4-29 
34. S. Kumar, K. Tamura, M. Nei, Comput. Appl. Biosci. 10, 189-191 (1994)

35. IBGE-Instituto Brasileiro de Geografia e Estatística. (2015), http://www.ibge.gov.br/home. Accessed 12 October 2015
36. D.J. An, H.Y. Jeoung, W. Jeong, H.S. Lee, J.Y. Park, B. Kim, Virus Genes 42, 208-211 (2011). doi:10.1007/s11262-010-0561-9

37. A.N. Lukashev, Rev. Med. Virol. 20, 327-337 (2010). doi:10. 1002/rmv.660 